\title{
A Estética da Recepção: o Leitor na economia da Obra e da História
}

Jefferson Cleiton de Souza ${ }^{\|}$

RESUMO: O presente trabalho tem por objetivo discutir como a estética da recepção, de Hans Robert Jauss, articulou a noção de leitor ao sistema literário, notadamente no que se refere à sua posição na economia de uma obra, bem como o seu papel na história da repercussão estética e social de tal obra. Para tanto, analisamos como as noções de leitor implícito e explícito, de base fenomenológica, assim como a de experiência estética relacionaram-se, nessa teoria, com as reflexões em torno da relação história, comunicação artística e recepção.

PALAVRAS-CHAVE: Estética da recepção, Jauss, leitor implícito e explícito.

ABSTRACT: The aim of this paper is to discuss how Hans Robert Jauss, the creator of the aesthetics of reception, has introduced the category of the reader into the literary studies especially when it comes to the importance of the reader to the understanding of the text, and to the history of a society and its literary system or, in other words to the way the formal elements of a literary work are organized and how they are related to aesthetic, ethic and moral evaluations. To do so, it is necessary to analyze how the conceptions of implied and actual reader, as well as of aesthetic experience, relate to questions of history, artistic communication and reception.

KEYWORDS: Aesthetics of reception, Jauss, implied reader and actual reader.

Até a década de 1960, os centros acadêmicos alemães mantinham uma tradição de pesquisas pautadas no historicismo e na filologia. Entretanto, a crise epistemológica enfrentada por essas duas disciplinas, aliada à democratização do ensino superior alemão e à crescente influência do estruturalismo francês nesses estabelecimentos de ensino, forçou as universidades da Alemanha Ocidental a buscar novas soluções para modernizar os estudos literários. Nesse contexto de mudanças estruturais, foi fundada, em 1966, a Universidade de Constança, concebida dentro de um espírito inovador no qual eminentes professores abdicaram de suas autonomias departamentais da área da linguagem para pensar de forma interdisciplinar os estudos literários. Essa configuração estimulou as pesquisas em torno da tradução do russo, possibilitando aos pesquisadores alemães o acesso aos textos do formalismo russo e do estruturalismo tcheco, bem como os estudos interdisciplinares acerca da Hermenêutica e da Poética.

Naquele mesmo ano, marcado pela reforma universitária alemã, Hans Robert Jauss foi convidado pelo professor Gerhard Hess a integrar o corpo docente daquele novo centro acadêmico. Na Universidade de Constança, Jauss encontrou um ambiente propício para repensar a pertinência do método historiográfico de análise literária de herança lansoniana, que estava relegado à ilustração da burguesia culta e aos currículos das escolas secundárias alemãs, como ele mesmo declara em sua conferência de 1967, intitulada A história da literatura como provocação à teoria da literatura. Em suma, suas investiga-

Jefferson Cleiton de Souza é mestre em Teoria da Literatura pela Universidade Federal de Pernambuco - Recife. Contato: jefferson.literatura@uol.com.br 
ções ambicionavam restabelecer o encontro da literatura com a história, ou melhor, da sociedade com o sentido das obras literárias, contudo sem aderir à orientação mecanicista da relação entre obra de arte e história, tal como foi pensada por Lanson.

Diante de tal panorama, Jauss propôs um método de investigação literária que visava, por um lado, dar uma resposta negativa tanto ao marxismo da Alemanha Oriental quanto aos estudos imanentistas do Estruturalismo francês e, por outro lado, revitalizar a historicidade nos estudos literários. Essa proposta culminou na criação da estética da recepção, método de investigação literária que manteve um profícuo diálogo com a hermenêutica de base fenomenológica e histórica do filósofo alemão Hans-Georg Gadamer, ex-professor de Jauss, assim como com o estruturalismo tcheco, tributário também, de certo modo, da corrente filosófica fundada por Husserl. Tal orientação, por sua vez, evidenciou o avanço da teoria de Jauss: aproximar os estudos da história da literatura das teorias que se ocupavam com a promoção do sentido, como a hermenêutica e a fenomenologia.

Assim, através das traduções e dos debates em torno dos textos tchecos, realizados pelo grupo de Constança, o mentor da estética da recepção entrou em contato com as ideias de Roman Ingarden, filosófo polonês de orientação fenomenológica, que influenciou profundamente os estruturalistas tchecos, sobretudo Mukarovsky e Vodicka. De acordo com Gloria Vergara:

\footnotetext{
Segundo Pozuelo Yvancos, o que Jan Mukarovsky e seu discípulo Felix Vodicka fizeram no Círculo de Praga foi potencializar o método de Ingarden ao subtraí-lo de seu a-historicismo e individualismo e submergi-lo no processo histórico-coletivo [...]. Mukarovsky fala de um fenômeno de concretização movediço e variante que atualiza uma série de normas de caráter social. (VERGARA 2007, p.118-119, tradução nossa)
}

Em face disso, o círculo linguístico de Praga contribuiu para o projeto de Jauss na medida em que Mukarovsky, assim como Ingarden, diferiu o objeto artístico do objeto estético. Para esses dois últimos estudiosos, enquanto o primeiro objeto era um artefato, o segundo era um produto da "recepção". No entanto, apesar de ambos salvaguardarem, em seus respectivos estudos, a ontologia da obra e afastarem-se de uma concepção essencialmente subjetivista da experiência estética, Mukarovsky, fiel aos princípios do estruturalismo tcheco, avançou em relação às ideias de Ingarden quando compreendeu a obra de arte literária em uma relação sistêmica com os fenômenos sociais. Essa resposta do estruturalista tcheco a tal impasse possibilitou aos estudos literários a consciência de que as estruturas da obra de arte literária estabelecem uma forte relação com as normas e valores introjetados por um corpo social.

Zilberman (1989) avalia que, a partir das ideias dos integrantes do círculo linguístico de Praga, o valor estético deixa de se confundir com algo fixo e substancial para se tornar histórico e dinâmico. Com essas inovações, as normas literárias passaram a ser consideradas a partir de uma “estabilidade precária”, já que, para Mukarovsky, nenhuma obra literária assume por inteiro as convenções literárias de seu tempo, na medida em que elas se originam da dialética entre aceitação e ruptura. De fato, Mukarovsky incorporou às suas reflexões um importante estudo relacionado à evolução das formas 
literárias ao longo da história, desenvolvido pelo formalista Tynianov. Para esse russo, os gêneros não se desenvolvem de forma autônoma através dos séculos, mas os seus “traços", a encenação de sua linguagem e os seus componentes extralinguísticos, modificam-se na economia das transições dos sistemas literários (TYNIANOV, 1973).

Por seu turno, Felix Vodicka, discípulo de Mukarovsky, contribuiu decisivamente para o método de Jauss, pois ele pensou de forma mais sistemática a posição do público no sistema literário. Diferentemente de Roman Ingarden, que entendia as concretizações voltadas para o preenchimento das lacunas e indeterminações das narrativas pelo leitor, Vodicka as redimensionou para os códigos e normas literários e extraliterários pressupostos pelo público. Assim, ele estruturou uma concepção de leitor imerso num mundo de experiências literárias, que, consequentemente, o familiarizava com as convenções, códigos, normas e valores artísticos de uma determinada época histórica.

Nesse sentido, o estruturalista tcheco não concebe o público apenas como uma estrutura do texto, mas como um agente ao qual o texto se dirige e de quem reclama apreensão, interpretação, validação e avaliação. Com isso, ele ambicionou criar uma história da repercussão das obras literárias que teria como ponto de aferição as reações do público face à recepção de obras. Ele propôs o plano piloto de um estudo da história literária baseada no consumo da obra pelo público, pois, para ele, tal investigação pressupunha os seguintes objetivos:

1. A reconstituição da norma literária e o conjunto de exigências literárias do período em questão;

2. A reconstituição da literatura do período em questão, isto é, a série de obras que são o objeto de avaliação, e a descrição da hierarquia de valores literários do período;

3. O estudo da concretização de obras literárias (atuais e anteriores), isto é, o estudo da obra particular em que a encontramos, segundo a concepção (especialmente em sua concretização pela crítica);

4. O estudo dos efeitos da obra nas esferas literárias e extraliterárias. (VODICKA, 1978, p.301)

Foi, portanto, relacionando esse plano piloto de Felix Vodicka com a concepção de história dos efeitos (Wirkungsgeschichte), de Gadamer, sensível à historicidade da compreensão e do sentido, que Jauss erigiu uma história da literatura centrada nos efeitos ético-estéticos das obras sobre variadas épocas históricas.

Para tanto, a metodologia de estudos de Jauss (2002), que visa à análise da experiência leitora do público, bem como a acolhida das obras literárias nos variados contextos históricos, pressupunha dois momentos na análise do fenômeno da recepção literária: o do efeito, momento condicionado pela estrutura (leitor implícito) e o da recepção propriamente dito, condicionado pelo público, isto é, pelos seus horizontes de expectativa.

Tal pressuposto evidencia que, para a orientação teórica da estética da recepção, o público constrói os sentidos e o valor das obras condicionados tanto pelos horizontes internos das obras quanto pelos seus contextos históricos. Por causa dessa noção, Jauss, sugestionado pela dialética socrática de Gadamer, asseverava que o princípio metodo- 
lógico da estética da recepção de reconstituir os horizontes de expectativas em que as obras foram criadas e recebidas possibilitava aos analistas da literatura tanto a recuperação das perguntas latentes que essas obras responderam provisoriamente face ao seu contexto de produção quanto das respostas dadas a elas na historicidade de seus efeitos.

Para Jauss, esse conhecimento revelaria o impacto das obras ao longo de sua recepção histórica e as produções de sentidos, o que demonstra a sua concordância com Hans-Georg Gadamer, pois, para ambos, não existe uma interpretação unívoca, e sim interpretações equívocas. Em outras palavras, o compreender-interpretar estaria intimamente relacionado ao devir histórico, isto é, ao acontecimento e evento. Por esse motivo, na esteira do autor de Verdade e método, Jauss desloca a noção da verdade do sentido para o poder da dialética socrática, isto é, para a relação dialógica, baseada na pergunta-resposta, entre o público e o texto.

Essa ideia de interação proposta por Jauss exigiu, além da categoria do leitor implícito - fundada por Roman Ingarden e potencializada por Wolfgang Iser - , um novo conceito de leitor que estabelecesse uma ponte entre as estruturas do texto e o mundo sócio-histórico em que a obra é acolhida. A estética da recepção batizou esse novo conceito de leitor de explícito. Robson Coelho Tinoco, em seu livro Leitor real e teoria da recepção, esclarece que o leitor explícito pode ser identificado como um indivíduo sócio-histórico que absorve determinada criação artística com as suas qualidades e defeitos, sendo o responsável pela recepção da obra propriamente dita, com as suas características ético-estéticas (TINOCO, 2010).

É justamente essa categoria, o leitor explícito, a responsável por atribuir valores estéticos às obras e por arregimentá-las aos dilemas éticos e morais vivenciados por uma determinada sociedade de leitores, ou seja, atualizá-las ao seu mundo histórico. Nesse sentido, poderíamos afirmar que a incorporação da dimensão ética aos estudos da leitura foi uma das maiores contribuições de Jauss a essa área de estudo.

Embora Vodicka (1978) já possuísse uma aguçada consciência sobre os efeitos da obra de arte na esfera extraliterária - como a relação de identificação do público com as personagens de ficção, a influência das personagens na estilização de tipos sociais de uma dada época e do impacto moral que determinadas obras causam numa sociedade -, relegou tais estudos ao escopo das ciências históricas. No entanto, Jauss, por sua vez, sem se afastar dos fenômenos eminentemente literários, buscou ultrapassar esse impasse através de um estudo sensível à relação dialética entre as configurações da obra, os dilemas sociais de seu contexto de produção e de recepção e a acolhida e o valor que os leitores explícitos lhe conferem. O que significa dizer que a teoria de Jauss, ao relacionar a experiência estética a uma propedêutica da reflexão ética, aproxima o mundo da obra do mundo da práxis dos leitores.

Por isso, Jauss deposita na reação dos leitores explícitos e no sistema literário a fonte de pesquisa do analista da estética da recepção. Nesse sentido, a análise da experiência estética do leitor, que, segundo Jauss, abarca a dimensão histórica do público leitor, só pode ser resgatada, historicamente, num sistema de referência objetivo de códigos literários, já que a noção de leitores dessa teoria corresponde a um sujeito de pré-compreensão, no qual estão introjetadas normas e valores estéticos que o habilitam a responder aos apelos da mudança do sistema literário. Portanto, essa reação, ou sintoma 
primário da interpretação, deve ser levado em consideração, incondicionalmente, pelo analista da teoria da recepção. Desse modo, Jauss conseguiu aclarar, cada vez mais, as nuances que envolvem as reações do público ao se debruçar sobre a relação entre o prazer e a comunicação artística. Para tal fim, ele empreendeu uma revisão crítica acerca das reflexões estéticas de Aristóteles, de Kant e dos estudos dos formalistas russos, no que se refere à percepção estética. Dessa forma, as investigações de Hans Robert Jauss começam pela experiência estética. Segundo ele:

A diferença fenomenológica entre compreensão e discernimento, entre a experiência primária e o ato da reflexão, com que a consciência se volta para a significação e para a constituição de sua experiência, retorna, pela recepção dos textos e dos objetos estéticos, como diferenciação entre o ato de recepção dos textos e dos objetos estéticos, como diferenciação entre o ato de recepção e o de interpretação do significado de uma obra; menos ainda, pela reconstrução da intenção de seu autor. A experiência primária de uma obra de arte realiza-se na sintonia com (Einstellungauf) seu efeito estético, isto é, na compreensão fruidora e na fruição compreensiva. Uma interpretação que ignorasse esta experiência estética primeira seria própria da presunção do filólogo que cultivasse o engano de supor que o texto fora feito, não para o leitor, mas sim, especialmente, para ser interpretado. (JAUSS, 2002, p.69)

Assim, ao propor essa plataforma de estudos voltada para a comunicação e o efeito estético da obra de arte literária, esse teórico estava, de certo modo, colocando em xeque a tradição da filologia alemã e o ensino de literatura na Alemanha. Jauss, ao articular as categorias aristotélicas da poeisis (produção da obra de arte), katharsis (comunicação artística) e asthesis (prazer estético da percepção) à noção kantiana de juízo estético e ao conceito de desfamiliarização e desautomatização do formalismo russo, constituiu um campo teórico fecundo para que os estudiosos pudessem aprofundar as reflexões em torno da experiência estética. Tais categorias possibilitaram a Jauss verticalizar as discussões em torno da retórica do texto, originalmente introduzidas por Aristóteles e Górgias, que foram fundamentais para que se desenvolvesse, nos estudos literários, uma maior compreensão sobre as economias estabelecidas entre os estratagemas das obras e as expectativas de um determinado público leitor.

A emersão dessas categorias e conceitos estéticos, desvelados e problematizados por Jauss, favoreceu, na segunda metade do século XX, um amplo debate em torno da problemática da comunicação artística.

Dessa forma, em pleno prestígio da teoria estética da vanguarda artística e da difusão da cultura de massa, a noção de comunicação estética propagada por Jauss foi, em parte, de encontro à teoria estética de Theodor Adorno, filósofo da escola de Frankfurt. Esse último instituiu uma teoria estética da negatividade, na qual os princípios de autonomia da arte, da refletividade estética e transgressão artística e do status quo foram tomados como indício de arte autêntica. Para Adorno (2008), a questão do prazer e da identificação narrativa na experiência artística moderna estava condicionada à manipulação do comportamento consumista promovida pela indústria cultural e a seu poder alienante.
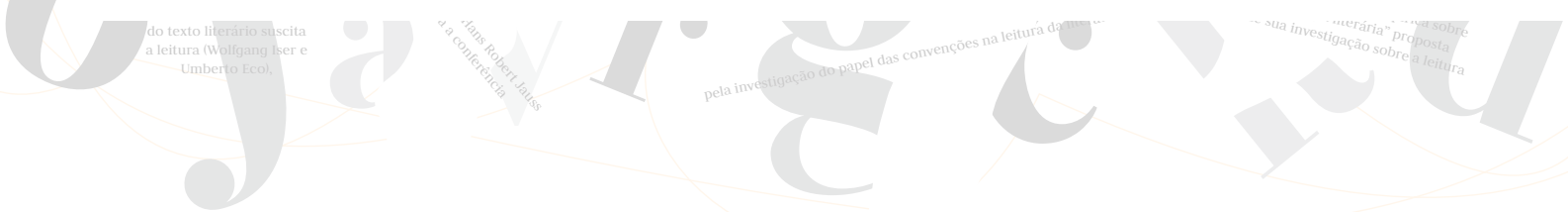
Advém desse conflito teórico travado com Adorno a dificuldade enfrentada por Jauss para reabilitar a noção de uma experiência estética pautada no prazer e na identificação estética. Primeiramente, porque para o autor de A história da literatura como provocação à teoria literária não era só a negatividade, isto é, a transgressão às normas literárias, perceptivas, artísticas e sociais que tinha o poder de promover mudanças de horizontes dos leitores e emancipá-los, mas também o caráter afirmativo da arte - o seu poder de comunicar os padrões dominantes da cultura. Essa crítica revela a oposição de Jauss em relação à noção de que a emancipação do leitor só seria possível mediada pela arte ascética e monódica, como são, nesse sentido, paradigmáticos a pintura de Jackson Pollock e o romance de Samuel Beckett.

Claramente, esse posiciomento de Jauss reflete a sua preocupação de pensar arte na economia da dinâmica social, assim como a partir de uma perspectiva que abarque tanto a análise sincrônica quanto a diacrônica. De acordo com a sua tese, as artes de vanguarda, após o seu período de impacto, acabam ao longo do tempo se tornando um horizonte afirmativo para o público à medida que se tornam clássicas:

Jauss afirma que o clássico seria, desta forma, o paradigma perfeito da transformação da negatividade em função afirmativa: através da tradição, a negatividade progressiva transforma-se em positividade progressiva. Com efeito, ele argumenta que a própria qualidade de ser clássico pressupõe uma segunda mudança no horizonte de interpretação, a qual oblitera a negatividade latente do antigo horizonte. A negatividade original da obra tornada clássica esconde-se, por efeito da tradição, atrás de uma aparente obviedade inquestionável, a qual poderia, por sua vez, revesti-la de aspectos semelhantes aos produtos da indústria cultural. Deve-se admitir, no entanto, que abordar as chamadas "obras-primas" por via de uma suposta afirmação do status quo é perder de vista a originária relação de tensão causada pelo texto e seu respectivo tempo histórico. (MIRANDA, 2007, p. 46)

Nesse sentido, infere-se que, para Jauss, as obras de arte, que estão imersas na historicidade, sempre nos "ensinam" algo na medida em que, para além de seu poder de impacto, põe-nos em contato com os nossos horizontes de expectativas, desvelando nosso mundo por meio das latências das obras.

Assim, a teoria proposta por Jauss buscou se ocupar com o destino da obra, com o seu poder comunicativo e as suas formas de recepção ao longo da história. Equivale a dizer que tanto o caráter transgressor da obra e sua repercussão como a forma como ela foi cultivada e apropriada pelo público interessam ao pesquisador do fenômeno da recepção.

Jauss desenvolveu dois estudos paradigmáticos que ilustram bem as preocupações que devem inquietar as pesquisas em torno do fenômeno recepcional. O primeiro estudo concentra-se na análise da repercussão que a obra Madame Bovary, de Gustave Flaubert, causou no momento de seu aparecimento no século XIX. Segundo Jauss, o escândalo social presente na obra de Flaubert visava "arrancar o leitor de Madame Bovary da certeza de seu juízo moral” (1994, p.56). Para ele, do ponto de vista metodológico da teoria da recepção, o analista da literatura só pode resgatar o impacto das obras através do próprio sistema literário, no qual as tramas entre as pré-concepções dos leitores e 
as normas vigentes da literatura e do mundo histórico urdem as experiências literárias. Por isso, conclui que não existe o grau zero da leitura, pois todos os leitores têm certa familiarização com as normas literárias vigentes de sua época, o que lhes permite reexperienciar ou romper com os seus códigos.

Desse modo, a derrocada da segurança do juízo moral da sociedade francesa, através do romance de Flaubert, dá-se, primeiramente, pelo tipo de narrativa adotado, uma narrativa impassível, que possibilita ao leitor perceber as coisas de um modo diferente; e, em segundo lugar, pela solução narrativa adotada pelo autor de Madame Bovary, que não se concilia com a harmonia da instituição familiar. Entretanto, mostra-nos Jauss, para ilustrar sua tese, que a negatividade da ficção de Flaubert, ao longo do tempo, foi se incorporando aos horizontes de leitura, tornando os seus valores estéticos consagrados pelo público. Isso nos leva a inferir que toda "positividade progressiva" se dá quando o que estava latente no social encontra as formas literárias responsáveis por estabelecerem a comunicação entre a cultura e arte, ainda que o seu público original não esteja suficientemente familiarizado.

O segundo estudo de Jauss objetivou, como nos lembra Zilberman (1989), compreender como a tragédia Ifigênia em Táuride, de autoria de Goethe, tornou-se ao longo dos tempos uma leitura compulsória e desinteressante nas escolas. Desafio que animou Jauss a percorrer a história da recepção desse clássico da literatura alemã, sob a orientação do horizonte da pergunta e da resposta, fato que revela a sua rejeição aos estudos direcionados à gênese do sentido da obra. Apoiando-se na investigação de obras que se utilizaram do mito clássico de Ifigênia, como Racine e o próprio Goethe, Jauss percebeu que as soluções narrativas dadas por cada um desses autores traziam implícita uma cosmovisão estética e histórica: Racine, pautado num racionalismo do século XVII, preferiu conduzir a sua tragédia para o conflito entre o arbítrio divino e a impotência humana, já Goethe, um iluminista de propensões românticas, optou por exaltar o triunfo da subjetividade contra a dependência mítica. Esse fato evidencia como as poéticas dialogam com os valores culturais, a fim de refratar o seu tempo e comunicar algo ao seu público.

No entanto, do ponto de vista recepcional, a obra de Goethe, que comunica um sistema de valores, no século XIX, passou a ser cultivada e valorada como numa categoria de beleza atemporal, tornando-a estéril para as futuras gerações. Fato que explica o motivo da falência do modelo historiográfico do ensino de literatura tanto nas escolas da década de 1960 como, de modo geral, nas de hoje - o escamoteamento do poder comunicativo das obras artísticas.

Diante desses exemplos paradigmáticos percebe-se que os eixos de estudos abertos pela teoria da recepção possibilitaram aos estudos literários arregimentar para as suas pautas de preocupação o fenômeno da recepção, categoria do sistema literário que, durante muitos anos, fora relegada ao esquecimento das análises literárias. Esse fenômeno possibilitou aos pesquisadores investigar de forma mais sistemática as tramas que inter-relacionam poéticas, culturas e mundos da práxis tanto do contexto de produção de determinadas obras como de sua comunidade de leitores ao longo do tempo. Tal possibilidade aclarou a compreensão em torno dos aspectos que envolvem o sistema de valores que se agregam às obras e o destino social que lhes é conferido, assim como elucidou o poder que determinadas obras possuem de denunciar, aludir e desrecalcar os padrões de comportamentos de uma sociedade de leitores historicamente situada. 
Entretanto, influentes comentadores de Jauss, como Antoine Compagnon e Terry Eagleton, apontam certa limitação às investigações desenvolvidas pela estética da recepção. O primeiro, em $O$ Demônio da teoria, e o segundo, em Teoria da literatura: uma introdução, advertem que o problema epistemológico das teorias do leitor de base fenomenológica - como é o caso da de Jauss - é que esse leitor é um pressuposto da concretização, isto é, que ele não é um ser de carne osso. De fato, essa é uma condição sine qua non para o desenvolvimento das pesquisas em torno da recepção, pois tal noção de leitor foi pensada para além de um empirismo, uma vez que a sua concepção nasce amalgamada à ideia de objeto artístico.

Nesse sentido, Roman Ingarden, em diálogo com Husserl, como já vimos, foi o grande responsável por transformar o leitor numa peça constitutiva do objeto estético. Por sua vez, Jauss reoxigena os debates em torno da leitura ao conceber a visada do leitor trespassador, isto é, o leitor explícito, que translada o mundo da obra para os seus dilemas históricos, por meio do impacto, ou do restabelecimento, ou das manifestações de determinados temas latentes em certas obras por uma dada sociedade, bem como pelas avaliações críticas dos leitores especializados. Posicionamento teórico que evidencia o desejo das teorias do leitor fenomenológico de não pensar a leitura fora de uma arrojada reflexão estética e de uma estabilidade fenomênica.

Desse modo, ao se conceber o leitor na economia da obra literária e da História, como atesta a estética da recepção, o estudioso da literatura pode ter sempre como pontos de análise concreta a retórica das obras, que explicita os estratagemas de efeitos e tipos de comunicação intencionados, assim como um sistema de valores que dialogam com o mundo da cultura. Essa concepção nos ajuda a compreender as reações e as avaliações estéticas dadas às obras e as discussões éticas que surgem em torno do conflito das fabulações. Fato que nos exige estabelecer um profícuo diálogo com todos os documentos da cultura que envolvem as obras em estudos, desde o ensaio crítico, correspondências entre autores, questões judiciais envolvendo a recepção de obras, censura, etc. Em síntese, as obras da visada do pesquisador da teoria da recepção são todas aquelas obras lidas e cultivadas por uma comunidade de leitores.

No entanto, vislumbra-se também outra possibilidade de estudo dentro da estética da recepção pautada nas inter-relações das soluções poéticas dada a uma determinada obra. Em seu estudo sobre Ifigênia, de Goethe, Jauss considera o trabalho de tradução de uma determinada obra para outro contexto cultural de extrema pertinência para se garantir a comunicabilidade da obra, desde que a tal tradução seja capaz de responder à insatisfação deixada pela obra traduzida. Essa noção, a nosso ver, coaduna-se perfeitamente com os estudos intersemióticos, sobretudo no que diz respeito à relação dialógica estabelecida entre a literatura e o cinema, através da qual temos acompanhado intrigantes esforços do último em desvelar latências da primeira. Além disso, em alguns casos, as soluções narrativas propostas pelo cinema, visando tornar contemporâneos os conflitos da ficção literária, chegam a irromper a unidade do mundo da obra. Nesse sentido, qualquer espécie de exemplificação desse intercâmbio, para nós, sujeitos letrados tanto na linguagem da literatura como na do cinema, seria um trabalho de Sísifo. 


\section{Refêrencias Bibliográficas}

ADORNO, Theodor. Teoria Estética. Rio de Janeiro: Edições 70, 2008.

COMPAGNON, Antoine. O Demônio da teoria: literatura e senso comum. Belo Horizonte: UFMG, 2006.

EAGLETON, Terry. Teoria da literatura: uma Introdução. São Paulo: Martins Fontes, 2003. JAUSS, Hans Robert. A história da literatura como provocação à teoria literária. São Paulo: Ática, 1994.

. O prazer estético e as experiências fundamentais da poiesis, aisthesis e katharsis. In: LIMA, Luiz Costa. (Org.). A literatura e o leitor: textos de estética da recepção. Rio de Janeiro: Paz e Terra, 2002.

. A estética da recepção colocações gerais. In: LIMA, Luiz Costa. A literatura e o leitor: textos de estética da recepção. Rio de Janeiro: Paz e Terra, 2002.

MIRANDA, Mariana Lage. Objeto ambíguo: arte e estética na experiência contemporânea, segundo H. R. Jauss. Dissertação (Mestrado em Filosofia) - Universidade Federal de Minas Gerais, Belo Horizonte, 2007.

SOUZA, Jefferson Cleiton de. A nova hermenêutica e a teoria da recepção em Jauss e Ricoeur. Dissertação (Mestrado em Letras). Universidade Federal de Pernambuco, 2011. TINOCO, Robson Coelho. Leitor real e teoria da recepção. São Paulo: Horizonte, 2010.

TYNIANOV, Juri. Da evolução literária. In: TOLEDO, Dionísio. Teoria da literatura: formalistas russos. Porto Alegre: Globo, 1973.

VERGARA, Gloria. La experiencia estética en el pensamiento de Roman Ingarden. Cultura: International Journal of Philosophy of culture and Axiology, [Romania], v. 8, p.117-136, ago. 2007. Disponível em: <http://www.international-journal-of-axiology. net/articole/nr8/art09.pdf>. Acesso em 03 mar. 2010.

VODICKA, Felix. A história da repercussão das obras literárias. In: TOLEDO, Dionísio. círculo linguístico de Praga: estruturalismo e semiologia. Porto Alegre: Globo, 1978.

ZILBERMAN, Regina. Estética da recepção e história da literatura. São Paulo: Ática, 1989.

ARTIGO RECEBIDO EM: 20 ago. 2012

ARTIGO ACEITO EM: 09 out. 2012

Referência ElETrônica: SouZA, Jefferson Cleiton de. A estética da recepção: o leitor na economia da obra e da história. Revista Criação \& Crítica, n. 9, p. 52-60, nov. 2012. Disponível em: < http://www.revistas. usp.br/criacaoecritica>. Acesso em dd mmm aaaa. 